1) Barnett, R. J., and Seligman, A. M.: Nat. Canc. Int., 14, 769, 1954. 2) Chiffelle, T. L., and Putt, F. A. : Stain Technol., 26, 51, 1951. 3) Currie, A. R., Symington. T., and Grant, J. K. : The Human Adrenal Cortex, Livingstone, Edinburgh \& London, 1962. 4) Deane, H. W., and Greep, R. O.: Endocrinology, 41, 243, 1947. 5) Elftman, H.: J. Histochem. \& Cytochem., 2, 1, 1954. 6) Elftman, H.: Stain Technol., 32, 29, 1957. 7) Grant, J. K., Symington, T., and Duguid, W. P. : J. Clin. Endocrinol. \& Metab., 17, 933. 1957. 8) Greep, R. O., and Jones, I. C. : Recent Progress in Hormone Res., 5, 197, 1950. 9) Halmi, N. S. : Anat. Rec., 112, 17, 1952, 10) Kluiver, H., and Barrera, E. : J. Neuropath. \& Exper. Neurol., 124, 400, $1953 . \quad 11)$ Maeda, R., Takada, R., and Yamagata, I. : Proc. Jap. Histochem. Ass., The Second Annual General Meeting, p. 211, $1961 . \quad 12$ ) Pearse, A.G.E. : Histochemistry, Theoretical and Applied, 2 Ed., Churchill, London, 1961. 13) Rennels, E. G., Anat. Rec., 115, 659, $1953 . \quad$ 14) Waiman, P., Reese, J. D., and Koneff, A. A. : Endocrinology, 31, 302, $1942 . \quad 15)$ Wallach, D. P., and Reineke, E. P.: Endocrino. logy, 45, 75, 1949. 16) Wolfe, J. M., and Chadwick, C. S. : Endocrinology, 20, 503, 1936. 17) Wolfe, J.M., and Wright, A. M. : Endocrinology, 23, 200, $1938 . \quad 18$ ) Wolfe, J. M. : Endocrinology, 29, 969, 1941.

\title{
Studies on Some Properties of Protein Granules in Parathyroid Cells of the Japanese Quail (Coturnix Coturnix Japonica)
}

\author{
Kazuyori YAMADA \\ Department of Anatomy, Nagoya University School of Medicine, Nagoya, Japan
}

In the course of our current attempts to cytologically demonstrate particular inclusions associated with the functional activity of parathyroid cells, three types of protein granules have been found which exhibit morphological features suggestive of their importance in the cytophysiology of the cells (Hara and Yamada, 1962 and 1963; Yamada, 1963). These granules were shown to react positively to coupled tetrazonium, 2, 2'-dihydroxy-6, 6'-dinaphthyl disulfide (DDD) diazo blue B and 2-hydroxy-3-naphthoic acid hydrazide (HNAH) diazo blue $B$ stains respectively and conceived to be concerned with either secretory of metabolic activity of the parathyroid cells. Although morphological features and chemocytological properties of the protein granules have been studied previously in the mammalian and amphibian parathyroid cells, precise examination still remains to be made on the granules occurring in the avian cells.

It is the purpose of this paper to study morphological features and chemocytological properties of the three types of protein granules in the parathyroid cells of the Japanese quail (Coturnix coturnix japonica) and to discuss the cytophysiological significance of the granules on the basis of the data obtained. 


\section{Materials and Methods}

Parathyroid glands were obtained from 5 male and 9 laying and 5 nonlaying female Japanese quails (Coturnix coturnix japonica) sacrificed by decapitation. The tissues were fixed in Carnoy's fluid and 1 or 2 per cent trichloracetic acid ethanol for a variety of periods ranging from 1 to 24 hours at room temperature, embedded in paraffin and sectioned at a thickness of 6 to $8 \mu$.

Methods for coupled tetrazonium reactive proteins and amino acids: Sections were reacted for coupled tetrazonium for proteins with phenol, indole and heterocyclic imidazole groups exactly as prescribed by Pearse (1960). Prior to staining some sections were treated with (1) 2,4-dinitrofluorobenzene, (2) performic acid and (3) benzoyl chloride, according to Danielli's (1953) formulae for distinguishing tyrosine, tryptophan and histidine residues of proteins from one another.

Methods for 2, $2^{\prime}$-dihydroxy-6,6'-dinapthyl disulfide (DDD) diazo blue B reactive proteins and amino acids: Sections were stained with the original DDD diazo blue B method (Barrnett and Seligman, 1952) for protein bound sulfhydryl groups. For the selective detection of sulfhydryl, disulfide and the both groups, some sections were subjected to previous thioglycolate, N-ethyl maleimide, iodoacetate and potassium cyanide treatments and combinations of these procedures (Barrnett and Seligman, 1954; Pearse, 1960).

Methods for 2-hydroxy-3-naphthoic acid hydrazide (HNAH) diazo blue B reactive proteins and amino acids: Sections were reacted for carboxyl groups of proteins as recommended by the original authors (Barrnett and Seligman, 1958). For the confirmation of the responsibility of protein bound carboxyl groups for the HNAH diazo blue B stain, prior methylation, saponification and methylation followed by saponification were performed according to Spicer and Lillie (1959). Furthermore, for the purpose of distinguishing protein bound side chain from alpha-acylamido carboxyl groups, some sections were treated with sodium hydroxide or ethanol following the acetic anhydride and pyridine stage of the HNAH diazo blue B technique (Karnovsky and Fasman, 1960; Karnovsky and Mann, 1961). Finally, a series of experimental procedures were performed on further sections which were treated with (1) pyridine alone, (2) acetic anhydride alone and (3) acetic anhydride alone followed by sodium hydroxide procedure; and with sodium hydroxide followed by (4) pyridine alone, (5) acetic anhydride alone and (6) acetic anhydride and pyridine, before being taken through the remaining stages of the HNAH diazo blue B method (Karnovsky and Mann, 1961).

Other methods: In order to examine correlations between the above reactions for proteins and amino acids and stainings for glycogen and ribonucleic acid in the parathyroid cells, some Carnoy-fixed sections were stained with PAS method (Pearse. 1960) and methylgreen pyronin technique (Modification of Brachet, 1940) in respective combinations with prior $\boldsymbol{\beta}$ amylase and ribonuclease digestions. 


\section{Results}

Coupled tetrazonium reactive protein granules: In the parathyroid gland of the quail the cytoplasm of the parenchymal cells is shown to contain a variable amount of coupled tetrazonium reactive fine granules which exhibit mostly a diffuse distribution (Fig. 1). However, such granules are hardly to be seen extracellularly. The staining intensity of these granules tends to decline slightly after pretreatment with 2,4-dinitrofluorobenzene and diminishes conspicuously following prior performic acid procedure, while previous benzoylation causes an effect similar to that produced by performic acid or abolishes the stainability.

2, 2'-dihydroxy-6, 6'-dinaphthyl disulfide (DDD) diazo blue $B$ reactive protein granules: In the quail parathyroid gland the DDD diazo blue B method can detect varying amounts of reactive granules of different sizes in the cytoplasm of the parenchymal cells, on the outer surface of the plasma membrane and within the extracellular spaces (Fig. 2). Prior thioglycolate reduction does not increase markedly the staining intensity of the granules, but does so only slightly. Pretreatment with either $\mathrm{N}$-ethyl maleimide or iodoacetate tends to abolish the stainability of the granules, and prior sequential treatment with the maleimide and potassium cyanide yields a faintly positive reaction of the granules.

2-hydroxy-3-naphthoic acid hydrazide (HNAH) diazo blue B reactive protein granules: In the parathyroid gland of the quail the HNAH diazo blue B method discloses the presence of a variable amount of reactive granules in the cytoplasm of the parenchymal cells (Fig. 3). In addition to such primary intracellular localization of the granules, their small amounts are often visualized within the extracellular spaces. Methylation blocks the HNAH diazo blue B reaction of the granules and methylation followed by saponification restores the reaction. Sodium hydroxide or ethanol treatment following the acetic anhydride and pyridine stage of the HNAH diazo blue $\mathrm{B}$ method results in an almost negative or exceedingly feeble stainability of the granules. Treatment with pyridine alone yields negative HNAH diazo blue $B$ reaction of the granules, while that with acetic anhydride alone causes their intensely positive reaction. After acetic anhydride alone and sodium hydroxide sequence the protein granules are found to exhibit doubtful or negative $\mathrm{HNAH}$ diazo blue $\mathrm{B}$ reaction. When sections are pretreated with sodium hydroxide and subsequently with pyridine alone, the reaction of the granules is doubtful, but, if the alkali treatment is followed by treatment with acetic anhydride alone or acetic anhydride and pyridine, the stainability of the granules tends to be a little more intense than that seen in the original HNAH diazo blue B stained sections.

All of the three types of protein granules in the parathyroid tissues are found to be more pronounced in amount and stainability in laying female quails than in male and non-laying female animals. In accordance with such tendency, the amount of glycogen in the parathyroid cells appears less and that of cytoplasmic ribonucleic acid seems larger in laying quails than in non-laying 


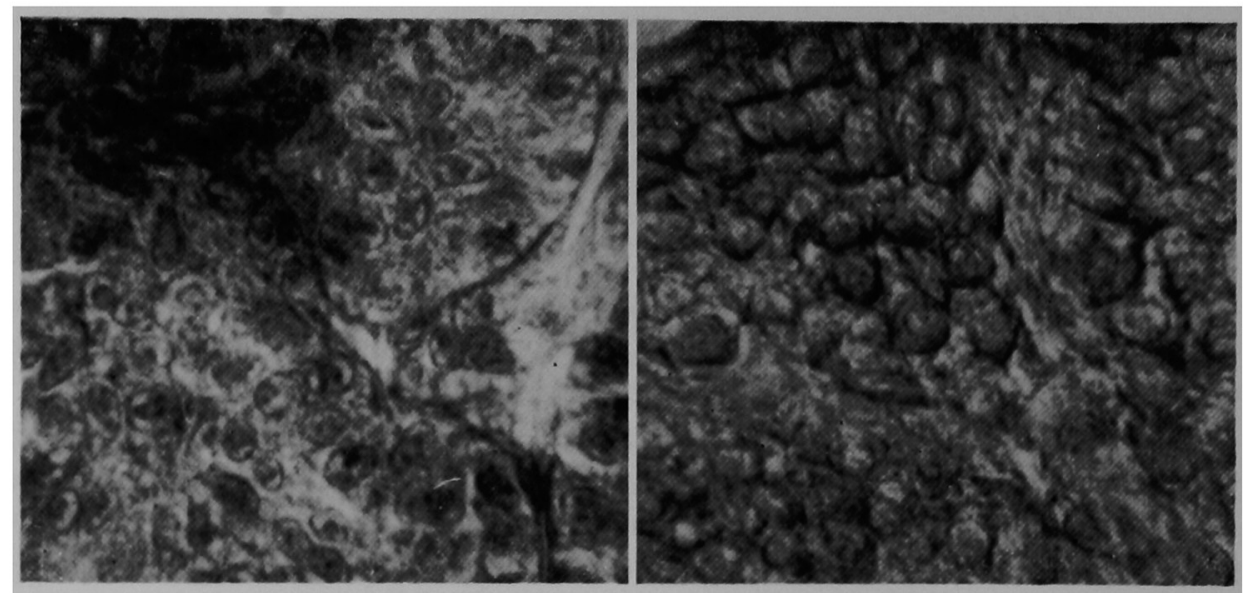

Fig. 1

Fig. 2

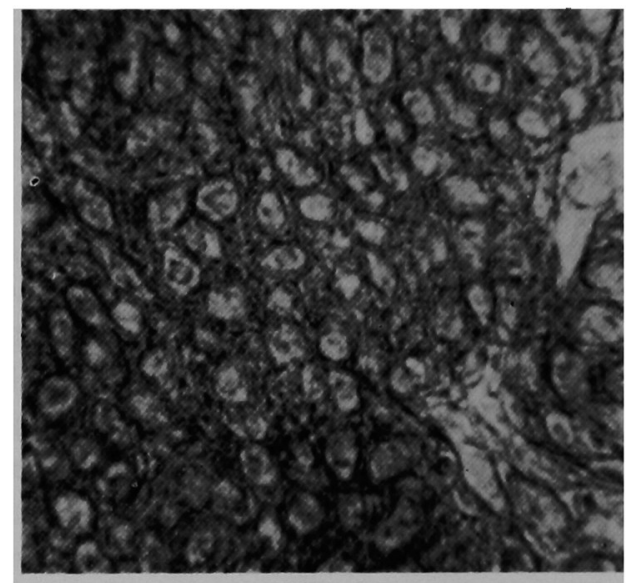

Fig. 3

individuals.

\section{Discussion}

Coupled tetrazonium reactive protein granules: Our previous data obtained from observations on oxyphil cells in the monkey parathyroid gland were suggestive of a possible mitochondrial nature of the tetrazonium reactive granules (Hara and Yamada, 1963), and in line with this, the distribution of similar granules is confined here within the cytoplasm of the quail parathyroid cells. In view of the Danielli's (1953) formulae concerning the effects of blocking experiments upon the tetrazonium reaction, the properties of the tetrazonium reactive fine granules in the quail parathyroid cells appear to indicate that the preponderant reactive groups of the granules must be indoles of their tryptophan residues. Therefore, it may be presumed that some of mitochondrial proteins in the cells involve materially a significant number of reactive tryptophan residues. 
2, 2'-dihydroxy-6, 6'-dinaphthyl disulfide (DDD) diazo blue $B$ reactive protein granules: The peculiar distribution pattern of DDD diazo blue $B$ reactive granules in the quail parathyroid gland appears indicative of their passage through the plasma membrane of the glandular cells and of their participation in the cellular activity of secretion. The effects of pretreatment with thioglycolate, $\mathrm{N}$-ethyl maleimide, iodoacetate, potassium cyanide and combinations of these treatments upon the DDD diazo blue $B$ reaction of the granules show that proteins with reactive sulfhydryl groups are predominantly responsible for the granules and protein bound disulfide groups are negligibly so. Such chemocytological property of the granules is worthy of note, in connexion with a biologically activating effects of sulfhydryl group containing reducing reagents like cysteine upon parathormone preparations (Rasmussen, 1958 and 1961). Thus, it appears reasonable to assert that this type of protein granules are composed of a protein carrying the avian parathyroid hormone and existing in association with the substance.

2-hydroxy-3-naphthoic acid hydrazide (HNAH) diazo blue B reactive protein granules: The chemocytological features of oxyphil cells in the monkey parathyroid gland have previously indicated that most of the demonstrable HNAH diazo blue $B$ reactive granules represent certainly a pattern of mitochondrial proteins in parathyroid cells (Hara and Yamada, 1963). This concept may be acceptable in terms of the preponderant intracellular localization of HNAH diazo blue $B$ reactive granules observed in the quail parathyroid cells. However, the extracellular presence of a small amount of the granules appears to suggest the possibility that they may be associated in part with the cellular activity of secretion. Taken altogether, the $\mathrm{HNAH}$ diazo blue $\mathrm{B}$ reactive granules are conceived to be dual in their cytophysiological significances; their majority appear to display a pattern of mitochondrial proteins and their small amount might be concerned with secretion in the parathyroid cells. The effects of methylation and methylation saponification sequence confirm that protein bound carboxyls are the reacting groups of the granules. From the blocking effect of sodium hydroxide and ethanol on the HNAH diazo blue B reaction of the granules the reactive carboxyls are concluded to be of side chain in nature (Karnovsky and Fasman, 1960; Karnovsky and Mann, 1961). This deserves particular interest in view of the biochemical data that parathyroid hormone preparations involve a significant number of glutamic and aspartic acid residues (Rasmussen, 1961) and therefore of side chain carboxyl groups in them. Thus, the latter of the above ideas on the cytophysiological significance of the granules may be likely. The results of a series of experimental procedures performed on the HNAH diazo blue B reaction of the granules appear to indicate that the granules stain largely in a mechanism proposed by Karnovsky's school.

The parathyroid cells of laying female birds are conceivably higher in secretory activity than those of male and non-laying female animals, since in the former animals serum calcium level tends to be lowered by steady excretion of the mineral for formation of egg-shell. Chemocytological com- 
parison of the parathyroid cells between laying and non-laying individuals is, accordingly, taken to suggest that the cytophysiological significances of the three typse of protein granules advocated appear valid and glycogen and ribonucleic acid contents seem to be well correlated with the amount of the granules in the cells, perhaps through the respective roles as energy source and protein synthetic index for the cellular activity of secretion.

\section{Summary}

Morphological and chemocytological studies have been made of three types of protein granules visualized in the parathyroid cells of the Japanese quail (Coturnix coturnix japonica). These granules are reactive for coupled tetrazonium, DDD diazo blue B and HNAH diazo blue B stains respectively. On the grounds of the morphological and chemocytological properties of the protein granules, glycogen and ribonucleic acid in the parathyroid cells, the cytophysiological significances of the granules have been discussed.

\section{Acknowledgements}

The author wishes to express his appreciation to Prof. Dr. Jun Hara for the constant encouragement and supervision in the course of this study. Further, he is grateful to Dr. Junzo Kito who has been so kind as to help him in obtaining the experimental animals.

\section{Explanation of Figures}

Fig. 1 Parathyroid gland of a Japanese quail (Coturnix coturnix japonica). Coupled tetrazonium reactive fine granules are visualized in the cytoplasm of parenchymal cells. Carnoy's fluid fixation, coupled tetrazonium stain. $\times 1300$.

Fig. 2 Parathyroid gland of a Japanese quail (Coturnix coturnix japonica). DDD diazo blue $B$ reactive granules are seen in the cytoplasm of parenchymal cells and scattered within the extracellular spaces. Trichlor acetic acid ethanol fixation, DDD diazo blue B stain. $\times 1300$.

Fig. 3 Parathyroid gland of a Japanese quail (Coturnix coturnix japonica). HNAH diazo blue B reactive granules are distributed primarily in the cytoplasm of parenchymal cells, while being scantily dispersed within the extracellular spaces. Carnoy's fluid fixation, HNAH diazo blue B stain. $\times 1300$.

\section{References}

1) Barrnett, R. J. and A. M. Seligman: Histochemical demonstration of protein bound sulfhydryl groups. Science, 116 ; 323-327 (1952). 2) Barrnett, R. J. and A. M. Seligman : Histochemical demonstration of sulfhydryl and disulfide groups of protein. J. Nat. Cancer Inst., 14 ; 769-803 (1954). $\quad 3$ ) Barrnett, R. J. and A. M. Seligman : Histochemical demonstration of protein bound alpha-acylamido carboxyl groups. J. Biophys. Biochem. Cytol., 4 ; 169-176 (1958). 4) Brachet, J.: La détection histochimique des acides pentose nucleiques. C. R. Soc. Biol., 133; 88 (1940). 5) Danielli, J. F. : Cytochemistry : A critical approach. Wiley, New York, (1953). 6) Hara, J. and K. Yamada : Some features of the structure and histochemistry of the rat parathyroid gland. Z. Zellforsch., 57 ; 360-370 (1962). 7) Hara, J. and K. Yamada: Some chemocytological observations on the parathyroid gland of the Formosan Rock monkey (Macaca cyclopis). Nagoya J. Med. Sci., 26 ; 1-15 (1963). 
8) Karnovsky, M. J. and G. D. Fasman: A histochemical method for distinguishing between side-chain and terminal (alpha-acylamido) carboxyl groups of proteins. J. Biophys. Biochem. Cytol., 8; 319-325 (1960). 9) Karnovsky, M. J. and M. S. Mann: The significance of the histochemical resction for carboxyl groups of proteins in cartilage matrix. Histochemie, 2 ; 234-243 (1961). 10) Pearse, A.G.E. : Histochemistry, Theoretical and Applied. J. \& A. Churchill, London, (1960). 11) Rasmussen, H. : Effect of oxidation and reduction upon the biological activity of parathyroid hormone. Science, 128 ; 1347-1348 (1958). 12) Rasmussen, H. : Chemistry of parathroid hormone. The parathyroids. Charles C Thomas, Springfield (Ill.), 60-75 (1961). $\quad$ 13) Spicer, S. S. and R. D. Lillie: Saponification as a means of selectively reversing the methylation blockade of tissue basophilia. J. Histochem. Cytochem., 7 ; 123-125 (1959). 14) Yamada, K.: 2, 2'-dihydroxy-6,6'-dinaphthyl disulfide (DDD) diazo blue $B$ reactive granules in the parathyroid gland of the rat and toad. Experientia, 19 ; 486-487 (1963).

\title{
Histochemical Studies on the Intestinal Metaplasia of the Gastric Mucosa
}

\author{
Shigetoshi Ohkawa, Norihiko IwaI, Masahiko Ohbayashi, \\ Hiroshi Sugmoto, Sadaki Morita, Yuzo Kanematsu, \\ Yoshiaki OKUDA and Akima MrYoshr. \\ The First Division, Department of Internal Medicine, Faculty of Medicine, \\ Kyoto University. (Director: Prof. Gyoichi Wakisaka)
}

In the previous study ${ }^{1}$, authors reported correlation between activity of succinic dehydrogenase and acid secretory function of the gastric mucosa.

In the atrophic gastritis, gastric ulcer and gastric cancer, the intestinal metaplasia is frequently associated with these changes. Much attention has been paid to clarify the etiological relationship between intestinal metaplasia and gastric cancer ${ }^{2}$. Attempts were made to elucidate this problem by means of histochemistry of human biopsy specimens.

\section{Matrials and Methods}

Gastric suction biopsy was performed in the patients with gastritis, peptic ulcer and gastric cancer. The biopsy specimens were obtained from the body and the antrum of stomach through $x$-ray clacivoyance. The unfixed specimens were cut at 10 microns in thickness in a cryostat maintained at $-15^{\circ} \mathrm{C}$. and the following enzymes were stained: Succinic dehydrogenase (Nachlas et al. ${ }^{3)}$, NADH dehydrogenase (DPNH diaphorase) (Nachlas et al.) ${ }^{4)}$, Leucine aminopeptidase (Nachlas et al.) ${ }^{5)}$, Adenosine triphosphatase (ATP ase) (Wachstein $\&$ Meisel) ${ }^{6}$, Alkaline phosphatase (Gomori's cobalt method) ${ }^{7)}$ and Acid phosphtase (Gomori) ${ }^{8}$. 